\title{
Sentimentos de mães portadoras de HIV/Aids em relação ao tratamento preventivo do bebê
}

\author{
Evelise Rigoni - Universidade Federal do Rio Grande do Sul \\ Elena O'Donnell da Silva Pereira - Universidade Federal do Rio Grande do Sul \\ Fernanda Torres de Carvalho - Universidade Federal do Rio Grande do Sul \\ Cesar Augusto Piccinini - Universidade Federal do Rio Grande do Sul
}

\begin{abstract}
Resumo
O tratamento do bebê, voltado à prevenção da transmissão materno-infantil do HIV/Aids, ocorre em um momento em que ansiedades decorrentes do processo de maternidade somam-se àquelas relativas à condição de soropositividade da mulher. O objetivo deste estudo foi o de investigar os sentimentos de mães portadoras de HIV/Aids em relação ao tratamento preventivo do bebê. Foram entrevistadas seis mães portadoras de HIV/Aids, com idades entre 22 e 42 anos, selecionadas em centros de saúde. Análise de conteúdo qualitativa identificou quatro categorias temáticas relacionadas aos sentimentos das mães quanto: ao diagnóstico do bebê, à impossibilidade de amamentar, à saúde do bebê, ao tratamento preventivo do bebê. Sentimentos maternos de medo e ansiedade mostraram-se presentes e contrastaram com a confiança da mãe em um desfecho positivo do tratamento do bebê. Sentimentos ambivalentes mostraram-se também presentes, o que sugere a importância de se elaborar intervenções psicológicas junto a estas mães.

Palavras-chave: HIV; Aids; Maternidade; Tratamento; Transmissão materno-infantil.
\end{abstract}

\section{Seropositive mothers' feelings concerning the preventive treatment of the baby}

\begin{abstract}
The infant's treatment, directed to prevention of the mother-to-infant transmission of the HIV/Aids, occurs at a moment when anxiety related to motherhood and seropositivity condition are present. The study goal was to understand the feelings of seropositive mothers concerning the preventive treatment of the baby. Six seropositive mothers were interviewed, aged between 22 and 42 years old. They were selected from healthcare centers. Qualitative content analysis identified four thematic categories related to the feelings of mothers about: the baby's diagnosis, the impossibility of suckle, the infant's health, the preventive treatment of the baby. Maternal feelings of fear and anxiety were present, as well as confidence in a positive outcome of the baby's treatment. The presence of ambivalent feelings suggests the importance of psychological interventions for these mothers.
\end{abstract}

Keywords: HIV; Aids; Motherhood; Treatment; Mother-to-infant transmission.

\section{Introdução}

A infecção pelo vírus da imunodeficiência humana (HIV), causador da síndrome da imunodeficiência adquirida (Aids), é considerada pela Organização Mundial da Saúde (OMS) a epidemia de maior gravidade dos últimos 50 anos. Estima-se que, em 2005, havia 38,6 milhões de pessoas vivendo com HIV/Aids no mundo e que 2,8 milhões de pessoas morreram em decorrência da doença (UNAIDS, 2006).

No Brasil, embora se tenha observado uma desaceleração da taxa de incidência de casos de HIV/Aids, estimativas de 2004 (Szwarcwald \& Souza Jr., 2006) indicavam prevalência de, aproximadamente, 600 mil casos de infecção pelo HIV/Aids na população de 15 a 49 anos. Diferentemente do momento inicial da epidemia, no qual os casos de HIV/Aids prevaleciam entre populações específicas, hoje se observa a presença da infecção na população geral. A epidemia tem apresentado mudanças em seu perfil, entre as quais se destacam o aumento de casos entre mulheres e o seu status de doença crônica (Oliveira \& Weinstein, 2004; Oliveira, Mann \& Oliveira, 2002). Diante desse cenário, os indivíduos portadores de HIV/Aids passaram a conviver com a infecção, vivenciando diferentes etapas de seu desenvolvimento na presença do vírus. No caso de mulheres, destaca-se a vivência da maternidade no contexto de infecção pelo HIV/Aids.

A gestação nesse contexto traz a possibilidade da transmissão materno-infantil do vírus, que consiste na transmissão do HIV da mãe portadora para o bebê pela exposição ao vírus durante gestação, trabalho de parto, parto ou aleitamento (Souza Jr., Szwarcwald, Barbosa Jr., Carvalho \& Castilho, 2004). A transmissão materno-

${ }^{1}$ Endereço para correspondência:

Universidade Federal do Rio Grande do Sul - Instituto de Psicologia

Rua Ramiro Barcelos, 2.600/111 - 90035-003 - Porto Alegre-RS

Email: everigoni@gmail.com 
infantil é a principal via de infecção pelo HIV na população infantil (Brasil, 2006a; Santos, Cabral \& Batista, 2005). Desde 1994, a transmissão materno-infantil do HIV tornou-se passível de prevenção, através dos resultados do ensaio clínico Pediatric Aids Clinical Trial Group 076, financiado pelo Ministério da Saúde dos Estados Unidos (Cardoso, 2006; Pluciennik, 2003). Os achados do estudo demonstraram que o uso da zidovudina (AZT) na gestação, parto e primeiras seis semanas de vida do bebê leva a uma considerável redução do risco de infecção do recém-nascido.

O Brasil tem adotado medidas de prevenção da transmissão materno-infantil desde 1996, voltadas à mãe durante gestação e parto, e ao bebê após o nascimento. As medidas profiláticas preconizam que seja oferecido o exame anti-HIV a todas as gestantes e, no caso de infecção pelo HIV, recomenda-se o uso de anti-retrovirais pela mãe durante gestação e parto. Além disso, realiza-se cesariana eletiva quando a carga viral materna for considerada alta ou desconhecida (Brasil, 2006a; Pluciennik, 2003). O tratamento preventivo do bebê, também chamado de profilaxia do bebê, inicia logo após o nascimento com o uso de zidovudina oral e a contra-indicação do aleitamento materno. Além disso, o bebê é acompanhado em centros especializados e deve se submeter a testagens sorológicas até a definição de seu diagnóstico, que ocorre até os 18 meses de vida (Brasil, 2006b; Negra, 2006). A adoção das medidas preventivas diminui o risco de infecção do bebê, que pode atingir taxas entre zero e $2 \%$ (Brasil, 2006a), e, quando nenhuma dessas recomendações é implementada, a probabilidade da transmissão materno-infantil do HIV pode ser de 25,5\% (Santos e cols., 2005).

A substituição do leite materno pelo leite industrializado consiste em uma importante etapa do tratamento preventivo do bebê (Brasil, 2006a; Lamounier, Moulin \& Xavier, 2004; Pluciennik, 2003). No entanto, Gamburgo, Munhoz e Amstalden (2002) ressaltam que a recomendação do leite artificial, no contexto do HIV/Aids, contraria a escolha prioritária pelo leite materno, tendo em vista os seus benefícios nutricionais, imunológicos e emocionais. Além disso, alguns estudos ressaltam que a amamentação no peito é percebida por muitas mulheres como um ato prazeroso e uma importante etapa para o estabelecimento do vínculo entre mãe e bebê, sendo uma forma de transmissão de afeto e segurança (Carrascoza, Costa Jr., Ambrosano \& Moraes, 2005; Coutinho \& Leal, 2005).

Nesse sentido, a recomendação de nãoamamentação pode mobilizar angústia na mãe portadora de HIV/Aids (Barbosa, 2001). A mãe também pode se deparar com sentimentos de medo e culpa de que o bebê seja infectado e não sobreviva à doença, sem falar no medo de sua própria morte e, por conseqüência, o temor pelo futuro da criança (Barbosa, 2001; Carvalho \& Piccinini, 2006; D’Auria, Christian \& Miles, 2006). Somase a isso o estigma social que recai sobre essas mães, cuja vivência pode provocar isolamento, comprometendo a obtenção de apoio das redes social e familiar (Siegel \& Lekas, 2002).

Além dos fatores relacionados à infecção pelo HIV/Aids e à possibilidade da transmissão maternoinfantil, essas mães também vivenciam ansiedades relativas ao próprio processo de maternidade. A transição para a maternidade inicia na gestação e se estende até os primeiros meses do bebê, sendo marcada por sentimentos ambivalentes e pela necessidade de adaptações psíquicas diante das mudanças e incertezas (Brazelton \& Cramer, 1992; Szejer, 2002). Desde a gestação, as mães apresentam diversos sentimentos e expectativas quanto a seus bebês, sua saúde e à própria interação mãe-bebê (Piccinini, Gomes, Moreira \& Lopes, 2004). Além disso, a maternidade também leva a rearranjos psicossociais, com mudanças de papéis e alterações nos padrões de relacionamento e de comunicação familiar, sem falar nas mudanças socioeconômicas, representadas pelas despesas que o nascimento e criação de um filho acarretam (Raphael-Leff, 1997).

Toda esta situação de maternidade fica mais complexa na presença de infecção pelo HIV/Aids. Além de todas as tarefas com as quais a mãe se depara, ela precisa lidar com a sua infecção e com o tratamento preventivo do bebê. Tais procedimentos, por estarem relacionados a todo o contexto da infecção, potencializam a presença de sentimentos ambivalentes que ainda precisam ser investigados. Nesse sentido, o objetivo do presente estudo foi investigar os sentimentos de mães portadoras de HIV/Aids em relação ao tratamento preventivo do bebê.

\section{Método}

\section{Participantes}

Participaram deste estudo seis mães portadoras de HIV/Aids, com bebês em tratamento preventivo da transmissão materno-infantil. O número de participantes atendeu à sugestão de Barker, Pistrang e Elliot (1994), que consideram que a saturação dos dados em estudos qualitativos pode ser atingida com amostras entre 5 e 10 participantes, especialmente quando se utilizam entrevistas ricas, com eixos temáticos definidos.

As mães do presente estudo tinham entre 22 e 42 anos e a idade dos bebês variou entre um e cinco meses, representando um período cuja condição sorológica da criança ainda estava sob investigação. Todas as mães haviam realizado as medidas preventivas da transmissão materno-infantil desde a gestação, em ambulatórios de infectologia de dois hospitais públicos da cidade de Porto 
Alegre. Em relação ao HIV/Aids, três mães haviam recebido o diagnóstico na gestação, enquanto as demais já sabiam da infecção antes da gravidez. As participantes que conheciam seu diagnóstico antes da gravidez preenchiam anteriormente critérios para Aids, porém estavam em boas condições de saúde. Estas, após o nascimento do bebê, seguiram com uso de anti-retrovirais, enquanto as outras três mães suspenderam o uso de medicações após o parto em virtude do resultado satisfatório de seus exames de CD4 e de carga viral.
Entre as mães que já se sabiam infectadas antes da gravidez, duas eram casadas e tinham outros filhos, enquanto uma estava solteira e era primípara. Entre aquelas que receberam o diagnóstico na gestação, duas eram solteiras e primíparas, enquanto uma estava casada e tinha outros filhos. Todas as mães e seus bebês residiam em Porto Alegre ou região metropolitana e apresentavam nível socioeconômico baixo, considerando sua escolaridade e ocupação. Os dados sociodemográficos das participantes encontram-se descritos na Tabela 1.

Tabela 1 - Dados sociodemográficos de mães portadoras de HIV/Aids

\begin{tabular}{ccccccccc}
\hline Caso & Idade & Instrução* & Ocupação & $\begin{array}{c}\text { Situação } \\
\text { conjugal }\end{array}$ & $\begin{array}{c}\text { Número } \\
\text { de filhos }\end{array}$ & $\begin{array}{c}\text { Sexo do } \\
\text { bebê }\end{array}$ & $\begin{array}{c}\text { Idade do } \\
\text { bebê }\end{array}$ & $\begin{array}{c}\text { Tempo de } \\
\text { diagnóstico de HIV }\end{array}$ \\
\hline M1 & 25 & EMC & secretária & solteira & 1 & masculino & 1 mês & 5 anos \\
M2 & 42 & EFI & dona de casa & casada & 5 & masculino & 2 meses & 7 anos \\
M3 & 23 & EMI & $\begin{array}{c}\text { desempregada } \\
\text { vendedora }\end{array}$ & solteira & 1 & feminino & 5 meses & 8 meses \\
M4 & 23 & EFI & casada & 2 & feminino & 1 mês & 7 meses \\
M5 & 22 & EMC & $\begin{array}{c}\text { técnica em } \\
\text { enfermagem } \\
\text { secretária }\end{array}$ & solteira & 1 & feminino & 5 meses & 10 meses \\
M6 & 32 & EMC & casada & 5 & feminino & 2 meses & 4 anos \\
\hline
\end{tabular}

*EFI = Ensino Fundamental Incompleto; EMI= Ensino Médio Incompleto; EMC= Ensino Médio Completo

\section{Delineamento, procedimentos e instrumentos}

Foi utilizado um delineamento de estudo de casos coletivo (Stake, 1994) para investigar qualitativamente os sentimentos de mães portadoras de HIV/Aids em relação ao tratamento preventivo do bebê. $\mathrm{O}$ estudo foi inicialmente aprovado pelo comitê de ética responsável por um dos dois hospitais nos quais a pesquisa foi realizada (Grupo Hospitalar Conceição - Prot. no 68/05). As equipes técnicas dos ambulatórios de infectologia desses hospitais encaminharam as mães que participaram do presente estudo, com base nos critérios descritos acima. As que concordaram em participar assinaram o Termo de Consentimento Livre e Esclarecido e responderam à Entrevista sobre Dados Demográficos do Casal (GIDEP, 1998), que investigou aspectos sociodemográficos, tais como idade, escolaridade, estado civil, profissão, número de filhos, assim como informações sobre o seu companheiro, quando fosse o caso. Na seqüência, realizou-se a Entrevista sobre a Maternidade em Situação de Infecção pelo HIV (Carvalho \& Piccinini, 2005). Trata-se de uma entrevista estruturada que tem por objetivo investigar sentimentos de mães portadoras de HIV/Aids relacionados ao diagnóstico, à maternidade, ao próprio tratamento e ao tratamento do bebê. A entrevista é constituída por cinco conjuntos de questões, envolvendo os seguintes temas: história da infecção pelo HIV/Aids (ex.: "Eu gostaria que tu falasses sobre como foi que o HIV entrou na tua vida"); notícia da gravidez e história da gestação (ex.: "Eu gostaria que tu falasses sobre a tua gravidez, desde o momento em que tu ficaste sabendo até agora"); tratamento da mãe e do bebê (ex.: "Como está sendo o teu tratamento e o do teu bebê até o presente momento?"); relação mãe-bebê (ex.: “Tu poderias me contar um pouco sobre como está a tua relação com o teu bebê?); e, por fim, expectativas futuras da mãe (ex.: "Eu gostaria que tu me falasses sobre o que tu esperas do futuro"). A entrevista foi realizada com cada mãe de forma semidirigida e teve duração aproximada de 90 minutos. Todas as entrevistas foram gravadas em audiocassete $\mathrm{e}$ posteriormente transcritas para fins de análise.

\section{Resultados}

Análise de conteúdo qualitativa (Bardin, 1979) foi utilizada para se investigar os sentimentos das mães portadoras de HIV/Aids em relação ao tratamento preventivo do bebê. Após a transcrição das entrevistas, procedeu-se a leituras exaustivas do material para a identificação de uma estrutura de categorias que representasse os sentimentos maternos. Conforme classificação de Laville e Dione (1999), utilizou-se então o modelo aberto de definição de categorias, já que estas 
foram determinadas a partir do conteúdo coletado, sem terem sido estabelecidas a priori. A análise realizada baseia-se na construção iterativa de uma explicação em que, conforme os autores, o investigador elabora uma explicação lógica do fenômeno, inter-relacionando as categorias, subcategorias e interpretações. Durante as análises, destacaram-se as semelhanças e as particularidades entre os casos, tendo em vista as diferenças individuais e histórias clínicas de cada participante. Duas das autoras do presente estudo trabalharam na identificação e classificação dos relatos envolvendo os sentimentos maternos. Eventuais discordâncias entre elas foram dirimidas por meio de discussão e, quando necessário, contou-se com a apreciação de um juiz. Para fins de análise, foram criadas quatro categorias temáticas baseadas nas próprias respostas das mães, que permitiram examinar os seus sentimentos quanto: 1) ao diagnóstico do bebê; 2) à impossibilidade de amamentar; 3) à saúde do bebê; e 4) ao tratamento preventivo do bebê. Cada uma dessas categorias será exemplificada a seguir com relatos das mães e, posteriormente, discutida conjuntamente.

\section{Sentimentos quanto ao diagnóstico do bebê}

Esta primeira categoria se refere aos sentimentos das mães em relação ao diagnóstico de HIV/Aids no bebê e suas possíveis reações. Os relatos envolveram sentimentos de medo e culpa ante a possibilidade de um diagnóstico positivo, e de confiança, satisfação e alívio diante do eventual diagnóstico negativo. Considerando o medo em relação ao diagnóstico do bebê, várias mães (M2, M3, M4, M5) mencionaram angústia e preocupação quanto à possibilidade de um diagnóstico positivo:

Eu pensava: Deus o livre eu ficar grávida, vai nascer no nenê [o HIV]. [...] Eu tenho medo, antes de ver os exames vou ficar com essa dúvida. [...] Por isso en não deixo judiar dele, tem que cuidar mais dele, ter mais cuidado com ele. Eu tenho medo, ele se gerou em mim e o meu sangue já tinha problema. (M2)

Eu me preocupo, quero que ela não seja positiva, que não tenha essa doença. (M4)

Tal medo mostrou-se presente mesmo entre as mães cujos bebês já haviam tido resultado provisório negativo para HIV/Aids:

O último exame [definitivo] ainda não ficou pronto, né! [...] Fico pensando que se os dois [exames provisórios] deram negativo, o próximo também vai dar, mas ainda tem uma remota chance de dar positivo e eu estou preocupada com isso, fico um pouco apreensiva. (M5)
Por outro lado, duas mães (M6, M1) não fizeram referência ao medo do diagnóstico e demonstraram sentir confiança quanto ao mesmo:

O infecto me disse que a cada 300 mulheres que ficam grávidas, duas, no máximo, nascem com o bebê soropositivo, porque a mulher não fez o tratamento direito. Se eu fizesse o tratamento direito ia diminuir muito as chances do meu bebê nascer soropositivo. Eu sempre fiz meu tratamento direitinho e durante a gravidez. eu fui mais à risca ainda, para não ter perigo mesmo. [...] Agora vamos ver, ele tem os examezinhos dele para fazer mas, acredito eu, que ele não tenha nada. (M1)

Como eu me cuidei durante toda a gestação e me cuido desde que eu soube do HIV, sei que as chances são minimas do meu bebê ter HIV. (M6)

Já várias mães (M2, M4, M5) demonstraram o quanto sentiam dificuldades em pensar na possibilidade de um resultado positivo para seus bebês: "Seria horrível, não gosto nem de pensar" (M4). Uma das mães (M3) mencionou sentimentos de culpa diante de um possível diagnóstico soropositivo do bebê: "Eu ia chorar muito, ia ver que a culpa ia ser toda minha" (M3). Já outra mãe revelou o temor de que o bebê viesse a falecer em decorrência do vírus:

Eu vou cuidar mais dele, dar o remédio certinho para não ter o risco de dali a um ano, dois anos, Deus o livre, da criança vir a falecer. Esse que é o meu medo, tenho medo disso aí. (M2)

Com relação a um possível diagnóstico negativo para $\mathrm{HIV} /$ Aids no bebê, todas as mães mencionaram sentimentos de satisfação e alívio: "É tudo o que eu quero!" (M4); "Eu ia me sentir feliz, né, da criança não ter este problema. Não é porque eu tenho que a criança vai ter, vou me sentir mais feliz ainda" (M2). Entre as falas, destaca-se a de uma mãe, que remete à idéia de "dever cumprido" em relação ao diagnóstico negativo do bebê: "Eu vou ver que foi um trabalho que eu fiz que foi cumprido. A minha missão com ela foi cumprida, eu consegui salvar ela" (M3).

\section{Sentimentos quanto à impossibilidade de amamentar}

Esta categoria refere-se os sentimentos que as mães relataram diante da recomendação de não amamentação enquanto meio de prevenção da transmissão materno-infantil do $\mathrm{HIV} / \mathrm{Aids}$. Os relatos envolveram tanto ausência de preocupações, como sofrimento e tristeza pela impossibilidade de amamentar. Algumas mães (M1, M2, M5) falaram da alimentação do bebê enquanto mais uma tarefa da

Psico-USF, v. 13, n. 1, p. 75-83, jan./jun. 2008 
rotina de cuidados com a criança, sem demonstrarem preocupações específicas: "A única coisa que me preocupa é se ele tem [o HIV], nas outras coisas está tudo bem, ele dorme bem, mama bem"(M2); "Ele é supercalmo [...], ele só chora quando está com vontade de mamar, ou quando ele faz xixi ou cocô, que ele está querendo que troque ele [...], ele é bem tranqüilo" (M1).

Entretanto, outras mães (M3, M4, M6) relataram sofrimento e tristeza diante da impossibilidade de amamentarem seus bebês:

O fato de não poder amamentar é o que me incomoda, ver as outras mães amamentando e eu não poder é difícil. (M6) Eu fiquei tão triste. Eu falei: Meu Deus, [...] queria dar de mamar para minha filha só que não posso. Vou ter que agüentar as dores. [...] o leite do peito é o melhor leite que tem para dar de mamar para o teu filho. Quando tu ganhas um filho tu quer dar de mamar para ele, não quer leite de lata. Ai eu me senti assim, mal com isso. Até hoje eu me sinto mal. Meu sonho era ter dado de mamar para minha filha [...] Eu tenho medo dela não engordar, dela ficar ruim. Mas, graças a Deus, ela está bem gorda, está com seis quilos. (M3)

Isso ai que eu sofri um ponco mais, eu olhava as mãezinhas segurando o peito, meu sonho era sempre este. Por isso que eu chorava mais e mais. [...] Tem aquilo de que leite materno é melhor, mas lá [grupo de gestantes] elas explicam que, desde que tu faças a mamadeira com todo amor e carinho, tu mesma dê, olhe para ela, fique conversando com teu bebê, vai ser o mesmo vínculo entre mãe e filho. [...] Daí, com o tempo, com as conversas eu fui entendendo. [...] Agora já tirei essa besteira da minha cabeça. (M4)

\section{Sentimentos quanto à saúde do bebê}

Nesta categoria, foram incluídos os relatos das mães referentes à saúde e integridade física do bebê. Foram consideradas as falas que não estivessem relacionadas diretamente ao temor do bebê ser portador do HIV/Aids. Quatro mães (M1, M2, M3, M5) referiram ter sentido medo de um possível problema de saúde do bebê, durante a gestação:

Minha preocupação era sobre o tratamento, se ele [bebê] ia nascer com problemas ou não [...]. O médico trocou minha medicação porque disse que a que eu estava tomando podia dar alucinação no bebê [...] Quando eu fiquei grávida en estava tomando essa medicação, ai o médico falou para en suspender porque ela podia prejudicar o bebê. (M1)

Meu maior medo era dele nascer aleijado, com problema. Cheguei em casa bem triste e men marido perguntou por que en estava triste e en disse que era porque estava grávida de quatro meses. E se a criança nasce com problema? Ele disse que se Deus deu para nós é porque vai nascer bem, perfeitinho e que se nascer com defeito nós vamos ter que aceitar, né, porque é filho da gente”. (M2)

[Eu tinha a preocupação] de ver se estava bem formadinha. Quando ela nasceu eu comecei a contar os dedinhos dela para ver se estava tudo certinho. (M3)

Algumas mães (M2, M5) mencionaram ter se sentido mais tranqüilas em relação à saúde e integridade física do filho após o momento da ultra-sonografia e do parto, quando elas visualizaram o bebê:

Dá uma emoção [o momento da ultra-sonografia], porque durante a gestação en ficava assim, tinha medo assim, de repente ela ter alguma coisa, algum problema. Mas ai eu vi ela perfeitinha e fiquei feliz, dá uma emoção. (M5)

Eu senti uma emoção de ver ele bem perfeitinho [no parto], bem gordinho, me deu uma alegria [...]. Eu estava com medo, até antes de ver eu tinha medo, medo de nascer defeituoso, com problema. Mas não, graças a Deus, depois que ele nasceu eu pedi para as enfermeiras me mostrarem e ele estava bem perfeitinho. (M2)

Sentimentos quanto ao tratamento preventivo do bebê

Esta categoria reuniu sentimentos presentes entre as participantes no que diz respeito ao tratamento do bebê. Cabe mencionar que todas as participantes eram as principais responsáveis pela administração da medicação do bebê, embora algumas pudessem contar com o apoio de terceiros. Os relatos das mães envolveram sentimentos relacionados à satisfação com o tratamento do bebê, às dificuldades na administração da medicação e, à importância do apoio familiar no tratamento do bebê.

Algumas mães (M3, M5, M6) relataram satisfação pela aceitação da medicação por parte do bebê:

Ela está reagindo superbem [à medicação]. Ela não reclama para tomar, ela até fica chupando a seringa, acha docinho, está tomando bem. Fico feliz em ver ela reagindo bem à medicação. [...] Espero que ela não tenha o HIV e logo mais não precise de tratamento. (M6)

Ela adora [a medicação]. É só botar a seringa que ela adora! (M5)

O tratamento dela está sendo bom. Ela está vindo aqui, foi feito o exame CD4 e agora ela tem que mostrar para o médico. Ela não tem nada, né, se Deus quiser. [... É É uma criança fácil de tomar xarope, ela toma numa boa. (M3)

Já algumas mães (M1, M2) mencionaram angústia quanto a alguns problemas na administração da 
medicação do bebê, relativos a reações negativas deste ou a dificuldades pessoais de realizar o procedimento:

Num dos primeiros dias ele teve náusea. Ele tomava [a medicaşão] e, geralmente, era perto do mamá dele. Ai quando ia tomar o mamazinho eu já me preocupava porque ele acabava vomitando. (M1)

[Quanto à medicação do bebê] eu penso: Será que vai ser para sempre? É que tem horas que a gente esquece de dar. Ai, as crianças me dizerm que está na hora do remédio do bebê, eles mesmos me lembram. (M2)

Relatos sobre a dificuldade de dar a medicação também estiveram associados ao temor quanto à possibilidade de revelação do HIV/Aids a outras pessoas:

Tenho confiança de que [o resultado do exame] seja negativo, de que não precise mais tomar nenbuma outra medicacão, até porque depois dos quatro meses dele eu volto a trabalhar e como só a minha mãe sabe, é a minha mãe que vai ficar com o meu filho quando en voltar a trabalhar. Vai ser bastante complicado se ele for tomar medicacãa porque minha tia vai estar lá [na casa da mãe], vai querer saber o porquê da medicação, e isso complica. (M1)

Por fim, a importância do apoio familiar no tratamento do bebê foi referida por algumas mães (M1, M2, M3) como sendo um fator que proporcionava sentimentos de segurança na realização dos procedimentos necessários:

Para mim é ótimo [o apoio dos pais]. Até assim, quando en preciso vir no médico, eles já sabem qual dia é. Se é dia de chuva, não é bom eu estar andando na chwva, então meu pai vem me trazer. Agora, com o pequeninho, ele sempre me traz. nas consultas. Eles sempre me apoiaram muito. Para mim é ótimo. Nada melhor do que o apoio de pai e mãe. (M1) Eu tomo remédio para dormir, posso dormir e esquecer de dar remédio para minha filha. Eu preciso de alguém que me ajude a cuidar da minha filha, e eu acho que minha mãe está me ajudando a cuidar dela; é a melhor coisa que minha mãe faz neste momento. (M3)

\section{Discussão}

No que diz respeito aos sentimentos das mães portadoras de HIV/Aids quanto ao tratamento preventivo do bebê, os relatos das participantes centraram-se sobre o diagnóstico do bebê, a impossibilidade de amamentar, a saúde do bebê e o tratamento medicamentoso. Tomandose conjuntamente as falas das participantes relacionadas aos sentimentos quanto ao diagnóstico do bebê, constata-se que a possibilidade de um diagnóstico positivo para HIV/Aids no bebê era fonte de angústia constante para essas mães. Tal angústia é demonstrada pelas suas dificuldades em falar sobre um possível diagnóstico positivo. Aquelas que conseguiram falar sobre isso mencionaram o medo da morte do bebê e a culpa que sentiriam por transmitir HIV/Aids aos seus filhos, o que foi também revelado em outros estudos (Barbosa 2001; Carvalho \& Piccinini, 2006; D'Auria e cols., 2006).

Nesse sentido, o tratamento do bebê pode ser um recurso que proporcione alívio às mães, uma vez que as torna mais ativas diante da possibilidade da transmissão materno-infantil. É importante destacar que duas mães (M1, M6) que se sentiam mais confiantes em relação ao tratamento do bebê faziam parte do grupo das que já se sabiam infectadas antes da gestação e cujos tratamentos pessoais se mostravam efetivos até o momento da entrevista. Isso sugere que a vivência positiva do próprio tratamento para HIV/Aids pode aumentar a confiança no sucesso do tratamento do bebê. Já a mãe que sabia do seu diagnóstico antes da gestação (M2) e que demonstrava intensa preocupação quanto ao diagnóstico de seu bebê, apesar de seu bom estado de saúde, era a única participante que havia vivenciado situação de morte em decorrência da Aids (falecimento do ex-companheiro). Tal fato pode ter contribuído para exacerbar suas preocupações, uma vez que a infecção do próprio bebê poderia reforçar seu temor de que este também viesse a falecer. Nesse sentido, ter vivenciado perdas decorrentes da Aids pode ser um fator que incrementa a angústia diante da possível infecção do bebê, o que se mostra presente durante o processo de tratamento preventivo. Isso demonstra as particularidades e complexidades de cada caso investigado e a importância de se conhecer as vivências da mãe e os seus significados, em especial aquelas relacionadas ao convívio com o HIV/Aids. Os relatos também demonstraram que o temor de um diagnóstico soropositivo no bebê esteve bastante presente entre as mães, apesar de elas saberem do baixo risco de transmissão materno-infantil (Brasil, 2006a) quando medidas preventivas são realizadas.

Algumas mães não conseguiram falar de suas reações diante de um diagnóstico soropositivo do bebê, o que indica sua dor diante da possibilidade de infecção e morte do filho, além da culpa pela transmissão do vírus. $\mathrm{Na}$ verdade, o bebê já ocupa um lugar importante na representação materna desde antes da gestação e a ele são dirigidas expectativas e afetos (Piccinini e cols., 2004). Nesse sentido, a frustração de tais expectativas, quanto à confirmação de um filho infectado, pode ocasionar tristeza, luto e incremento da culpa materna. 
A análise dos relatos das participantes referentes à recomendação de não amamentar também revela que, para várias mães, não amamentar mobilizou muitas angústias associadas à função materna e à saúde do bebê. Conforme ressaltou Barbosa (2001), a associação entre maternidade e amamentação faz com que as mães portadoras de HIV/Aids sintam que estejam falhando enquanto mães. Além disso, elas podem se sentir frustradas por não desfrutarem do contato íntimo com o bebê proporcionado pela situação de amamentação, ou podem temer que a relação com seus bebês sofra algum prejuízo, em especial do ponto de vista afetivo. Entre os relatos, também estiveram presente temores quanto à saúde do bebê, uma vez que este se alimentava com o leite industrializado. Isso pode estar relacionado à ampla divulgação sobre os benefícios do leite materno, em especial para o sistema imunológico (Gamburgo e cols., 2002). Tal preocupação quanto à nutrição do bebê pode ser ainda maior nos seus primeiros meses de vida, quando a possibilidade de infecção é mais real, uma vez que ainda se desconhece seu diagnóstico definitivo.

A angústia quanto à impossibilidade de amamentar foi especialmente destacada por duas das três mães que souberam do HIV/Aids na gestação (M3, M4). Por outro lado, entre as três mães que já tinham o diagnóstico de HIV/Aids antes da gestação, duas delas (M1, M2) falaram da amamentação enquanto mais uma tarefa do cotidiano com o bebê, sem transparecer angústias específicas quanto a esse momento. É possível pensar que a angústia diante da amamentação também possa ser intensificada pelo impacto do diagnóstico, que exige da mulher uma rápida assimilação sobre sua condição de portadora de HIV/Aids e uma readaptação de sua imagem materna. Em contrapartida, aquelas que se sabiam portadoras de HIV/Aids antes da gravidez podem já ter assimilado sua nova condição e desenvolvido estratégias para lidar com o HIV/Aids, com redução desse impacto na sua imagem materna. No entanto, estudos mais específicos são necessários para compreender o impacto do diagnóstico de HIV/Aids nos sentimentos maternos quanto à impossibilidade de amamentar. No que diz respeito aos relatos das participantes, deve-se considerar ainda que, embora a contra-indicação da amamentação provocasse angústia e sentimentos ambivalentes nas mães, prevaleceu a atenção à recomendação e a aceitação do leite industrializado. Isso leva à pensar que o temor pela infecção do bebê e o cuidado dessas mães prevaleceu diante da frustração por não amamentar.

Considerando os sentimentos quanto à saúde do bebê, destacaram-se, nos relatos das mães, preocupações envolvendo malformação fetal. Embora tais preocupações encontram-se presentes na maioria das gestações

Psico-USF, v. 13, n. 1, p. 75-83, jan./jun. 2008
(Brazelton \& Cramer, 1992; Piccinini e cols., 2004), podese pensar que o HIV/Aids potencialize este temor, uma vez que a gestação já se encontra num contexto de infecção e vulnerabilidade. Embora o temor de malformações parecesse desaparecer no relato das mães após o nascimento do bebê, seguia o medo quanto a outros problemas de saúde do bebê associados à infecção pelo HIV/Aids.

Quanto ao tratamento preventivo do bebê, os relatos das mães evidenciaram satisfações e dificuldades. Em particular, a reação da criança diante da medicação demonstrou ter importante impacto sobre os sentimentos maternos. A aceitação da medicação pelo bebê pareceu tranqüilizar e amenizar a ansiedade da mãe quanto ao tratamento, possivelmente por se permitir acreditar que não estaria causando algum dano ou incômodo ao filho. No processo de transição para a maternidade, a mãe portadora de HIV/Aids se depara com diversos dilemas, como o medo de que a criança não sobreviva à doença, angústia por não poder amamentar, medo de sua própria morte e, por conseqüência, temor pelo futuro da criança (Barbosa, 2001; Carvalho \& Piccinini, 2006). Em meio a este cenário conflitivo, de angústias e perdas, deparar-se com a aceitação da medicação pela criança possibilita um certo alívio, como foi relatado por uma mãe (M6), que se mostrou muito feliz e satisfeita com a boa aceitação de seu bebê à medicação.

As mães também mencionaram a importância do apoio familiar no tratamento do bebê, sendo este um dos fatores de suporte e motivação para seguirem as prescrições de forma mais tranqüila. Isso também já havia sido destacado por Carvalho e Piccinini (2006), com relação ao período da gestação, onde o apoio familiar também se mostrou relevante. Por outro lado, a falta de apoio e o temor do preconceito, evidenciados no contexto do HIV/Aids (Siegel \& Lekas, 2002) parecem ser um obstáculo no momento da administração da medicação do bebê. Em geral, as mães do presente estudo se encarregavam da administração da medicação, porém, em alguns momentos, precisavam solicitar o auxílio de outras pessoas. Essa situação foi relatada com preocupação por pelo menos uma mãe do presente estudo (M1) pela possibilidade de que o segredo acerca do diagnóstico fosse revelado. Isso obviamente mobiliza muitas angústias nas mães, o que vem a se somar à sobrecarga de tarefas e cuidados comumente exigidos nos primeiros meses de vida de qualquer bebê. Assim, o temor da revelação do diagnóstico e do preconceito pode fazer com que a mãe procure menos auxilio na administração da medicação e nos cuidados do bebê, o que pode provocar seu isolamento e tornar esse momento ainda mais difícil.

Enfim, compreender os sentimentos de mães portadoras de HIV/Aids em relação ao tratamento 
preventivo do bebê ainda se constitui um desafio. Os resultados do presente estudo apontam para muitas ansiedades, culpas e esperanças, que se misturam aos sentimentos presentes no próprio processo de maternidade e interação com o bebê. Para que as mães realizem as recomendações de saúde de maneira mais tranqüila, é importante que elas tenham um espaço no qual tais sentimentos possam ser expressos. Isso sugere a importância de intervenções psicológicas junto a essas mães, que as auxiliem no processo de prevenção da transmissão materno-infantil, particularmente na vivência do tratamento preventivo do bebê. Tais intervenções, ao proporcionarem o alívio da ansiedade da mãe, poderão também ter um conseqüente impacto para o desenvolvimento do bebê.

\section{Referências}

Barbosa, R. E. S. (2001). Mulheres, reprodução e aids: As tramas da ideologia na assistência à saúde de gestantes HIV+. Tese de Doutorado. Rio de Janeiro: Escola Nacional de Saúde Pública - Fundação Oswaldo Cruz.

Bardin, L. (1979). Análise de conteúdo. (L. A. Reto \& A. Pinheiro, Trad.). São Paulo: Edições 70; Martins Fontes.

Barker, C., Pistrang, N. \& Elliot, R. (1994). Research methods in clinical and counselling psychology. England: Wiley.

Brasil (2006a). Recomendações para profilaxia da transmissão vertical do HIV e terapia anti-retroviral em gestantes. Brasília: Ministério da Saúde, Secretaria de Vigilância em Saúde, Programa Nacional de DST e AIDS.

Brasil (2006b). Guia de tratamento clínico da infecção pelo HIV em pediatria. Brasília: Ministério da Saúde, Secretaria de Vigilância em Saúde, Programa Nacional de DST e AIDS.

Brazelton, B. \& Cramer, B. G. (1992). As primeiras relaçoes. São Paulo: Martins Fontes.

Cardoso, E. M. (2006). Cuidando de crianças com HIV/AIDS. Em S. M. M. Padoin, C. C. Paula, D. Schaurich \& V. A. Fontoura (Orgs.). Experiências interdisciplinares em Aids: Interfaces de uma epidemia (pp. 173186). Santa Maria: Editora UFSM.

Carrascoza, K. C., Costa Jr., A. L., Ambrosano, G. M. B. \& Moraes, A. B. A. (2005). Prolongamento da amamentação após o primeiro ano de vida: Argumentos das mães. Psicologia: Teoria e Pesquisa, 21(3), 271-277.

Carvalho, F. T. \& Piccinini, C. A. (2005). Entrevista sobre a maternidade em situação de infecção pelo HIV. Em F. T. Carvalho (Org.). Maternidade em situação de infecção pelo HIV: Um estudo sobre os sentimentos de gestantes.
Dissertação de Mestrado. Porto Alegre: Universidade Federal do Rio Grande do Sul - Instituto de Psicologia.

Carvalho, F. T. \& Piccinini, C. A. (2006). Maternidade em situação de infecção pelo HIV/Aids: um estudo sobre os sentimentos de gestantes. Revista Interação em Psicologia $10(2), 345-355$.

Coutinho, J. \& Leal, I. P. (2005). Atitudes de mães em relação à amamentação. Estudo exploratório. Análise Psicológica, 23(3), 277-282.

D’Auria, J. P., Christian, B. J. \& Miles, M. S. (2006). Being there for my baby: Early responses of HIV-infected mothers with an HIV-exposed infant. Journal of Pediatric Health Care, 20, 11-18.

Gamburgo, L. J. L., Munhoz, S. R. M. \& Amstalden, L. G. (2002). Alimentação do recém-nascido: aleitamento natural, mamadeira e copinho. Fonoaudiologia Atual, 20(5), 39-47.

GIDEP - Grupo de Interação Social, Desenvolvimento e Psicopatologia (1998). Entrevista de dados demográficos do casal. Instrumento não publicado. Porto Alegre: Universidade Federal do Rio Grande do Sul - Instituto de Psicologia.

Lamounier, J. A., Moulin, Z. S. \& Xavier, C. C. (2004). Recomendações quanto à amamentação na vigência de infecção materna. Jornal de Pediatria, 80(5), 181-188.

Laville, C. \& Dione, J. (1999). A construção do saber: manual de metodologia da pesquisa em ciências humanas (H. Monteiro \& F. Settineri, Trad.). Porto Alegre: Artes Médicas Sul.

Negra, M. D. (2006). AIDS pediátrica: Aspectos clínicos. Em S. M. M. Padoin, C. C. Paula, D. Schaurich \& V. A. Fontoura (Orgs.). Experiências interdisciplinares em AIDS: interfaces de uma epidemia (pp. 139-160). Santa Maria: Editora UFSM.

Oliveira, S. B. \& Weinstein, C. (2004). Aids: duas décadas de epidemia, pandemia, vulnerabilidade social. O que vem depois? Em S. Broxado, M. A. Lima, C. Weinstein \& E. Rocha (Orgs.). Manual de prevenção do HIV/AIDS para profissionais de saúde mental (pp. 16-23). Brasília: Ministério da Saúde.

Oliveira, S. B., Mann, C. G. \& Oliveira, C. S. S. (2002) Sexualidade \& DST/AIDS: discutindo o subjetivo de forma objetiva. Rio de Janeiro: Instituto Franco Basaglia.

Piccinini, C. A., Gomes, A. G., Moreira, L. E. \& Lopes, R. S. (2004). Expectativas e sentimentos da gestante em relação ao seu bebê. Psicologia: Teoria e Pesquisa, 20(3), 223-232.

Pluciennik, A. M. A. (2003). Prevenção da transmissão materno-infantil do HIV: é mais caro identificar do que 
tratar a gestante soropositiva. Revista Associação Médica Brasileira, 49(1), 12-12.

Raphael-Leff, J. (1997). Gravidez: a história interior. Porto Alegre: Artes Médicas.

Santos, S. P. C., Cabral, A. L. \& Batista, M. F. P. (2005). Gestante HIV positiva: evento sentinela. Em Brasil, Boletim Epidemiológico Aids DST 2005 (pp. 10-13). Brasilia: Ministério da Saúde, Secretaria de Vigilância em Saúde, Programa Nacional de DST e AIDS.

Siegel, K. \& Lekas, H. M. (2002). Aids as a chronic illness: Psychosocial implications. Aids, 16, 69-76.

Souza Jr., P. R. B., Szwarcwald, C. L., Barbosa Jr., A., Carvalho, M. F. \& Castilho, E. A. (2004). Infecção pelo HIV durante a gestação: estudo sentinela-parturiente. Revista de Saúde Pública, 38(6), 764-772.

Stake, R.E. (1994). Case studies. Em N. Denzin \& Y. Lincoln (Orgs.). Handbook of qualitative research (pp. 236247). Londres: Sage.
Szejer, M. (2002). Uma abordagem psicanalítica da gravidez e do nascimento. Em L. Corrêa Filho, M. E. G. Corrêa \& P. S. França (Orgs.) Novos olhares sobre a gestação e a criança até os três anos. Saúde perinatal, educação e desenvolvimento do bebê (pp. 299-323). Brasília: LGE.

Szwarcwald, C. L. \& Souza Jr., P. R. B. (2006). Estimativa da prevalência de HIV na população brasileira de 15 a 49 anos, 2004. Em Brasil, Boletim Epidemiológico 2006 (pp. 11-15). Brasília: Ministério da Saúde, Secretaria de Vigilância em Saúde, Programa Nacional de DST e AIDS.

UNAIDS - Joint United Nations Programme on HIV/Aids (2006). 2006 Report on the global Aids epidemic. Joint United Nations Programme on HIV/Aids.

Recebido em junho de 2007 Reformulado em janeiro de 2008 Aprovado em fevereiro de 2008

Sobre os autores:

Evelise Rigoni é psicóloga pela Pontifícia Universidade Católica do Rio Grande do Sul, especialista em Psicologia Hospitalar pela Universidade Federal do Rio Grande do Sul e em Saúde Mental pela Residência Integrada em Saúde do Grupo Hospitalar Conceição. Atualmente é mestranda do Programa de Pós-Graduação em Psicologia da Universidade Federal do Rio Grande do Sul, sob orientação do prof. dr. Cesar Piccinini.

Elena O'Donnell da Silva Pereira é psicóloga pela Universidade do Vale do Rio dos Sinos, especialista em Psicologia Hospitalar pela Universidade Federal do Rio Grande do Sul e psicóloga concursada da Prefeitura de Arroio dos Ratos/RS.

Fernanda Torres de Carvalho é psicóloga pela Pontifícia Universidade Católica do Rio Grande do Sul, especialista em Saúde Coletiva pela Residência Integrada em Saúde da Escola de Saúde Pública, Rio Grande do Sul, é mestre e doutoranda do Programa de Pós-Graduação em Psicologia da Universidade Federal do Rio Grande do Sul, sob orientação do prof. dr. Cesar Piccinini.

Cesar Augusto Piccinini é psicólogo pela Universidade Federal do Rio Grande do Sul. Fez doutorado e pósdoutorado na University College London (Inglaterra). É pesquisador do CNPq e professor na Graduação e no Programa de Pós-Graduação em Psicologia da Universidade Federal do Rio Grande do Sul. 